\title{
Padronização, controle e accountability na política curricular paulista (2007-2018)
}

\author{
Márcia Aparecida Jacomini' (1) \\ Silvio Ricardo Gomes Carneiro" (D) \\ Ana Carolina Colacioppo Rodrigues III \\ Raphael Bueno Bernardo da Silvalv
}

RESUMO

Neste artigo, investigam-se as políticas curriculares da rede estadual de ensino de São Paulo entre 2007 e 2018 com o objetivo de compreender seus sentidos e significados. Em 2007 foi implantado um modelo padronizado de currículo, articulado à avaliação de desempenho das escolas e à bonificação docente. Com base em pesquisa documental, buscou-se entender a gênese desse modelo de política curricular originado nos anos 1990 e que culminou, em 2007, com a implantação do Programa São Paulo Faz Escola e, posteriormente, em 2012, com o Programa Escola Integral. Ambos os programas são tentativas de remodelar a escola com um currículo moderno, baseado nas pedagogias das habilidades e competências. Essas políticas curriculares reproduzem o tripé de uma "nova agenda" de políticas públicas, baseada em accountability, controle e padronização, alterando o sentido da qualidade da educação, reduzido ao escopo da "aprendizagem".

PALAVRAS-CHAVE

políticas curriculares; rede estadual de ensino de São Paulo; trabalho docente.

'Universidade Federal de São Paulo, Guarulhos, SP, Brasil.

"Universidade Federal do ABC, São Bernardo do Campo, SP, Brasil.

"'Pontifícia Universidade Católica de São Paulo, São Paulo, SP, Brasil.

IVSecretaria da Educação do Estado de São Paulo, São Paulo, SP, Brasil. 


\section{CURRICULAR POLICY STANDARDIZATION, CONTROL, AND ACCOUNTABILITY IN THE STATE OF SÃO PAULO (2007-2018)}

\section{ABSTRACT}

This paper investigates the curricular policies implemented in the education system of the state of São Paulo between 2007 and 2018, in order to understand their senses and meanings. In 2007, a standardized curricular model for São Paulo was implemented alongside a system including student performance evaluations and bonuses for teachers. Documents consulted in the elaboration of this paper reveal the genesis of this curricular policy model in the 1990s, a process that would culminate with the implementation of the São Paulo Faz Escola Program in 2007 and, later, in 2012, of the Escola Integral Program. Both programs are attempts to reshape schools through a modern curriculum based on a pedagogy of skills and competencies. These curricular policies reproduce a "new agenda" of public policies, which has been supported by the tripod of accountability, control, and standardization, changing the sense of quality of education, reduced to the scope of "learning".

\section{KEYWORDS}

curricular policies; São Paulo State education system; educational work.

\section{ESTANDARIZACIÓN, CONTROL Y ACCOUNTABILITY EN LA POLITICA CURRICULAR DEL ESTADO DE SÃO PAULO (2007-2018)}

\section{RESUMEN}

En este artículo investigamos las políticas curriculares implementadas en la red estatal de enseñanza de São Paulo entre 2007-2018, con el objetivo de comprender sus sentidos y significados. En 2007, se implementó un modelo de estandardización de currículo para São Paulo, articulado a la evaluación del desempeño de las escuelas y a la bonificación del docente. Con base en investigación documental, buscamos entender la génesis de ese modelo de política curricular originado en los años 1990 y que culminó, en 2007, con la implementación del Programa São Paulo Faz Escola y, posteriormente, en 2012, del Programa Escuela Integral. Ambos programas son intentos de remodelar la escuela a través de un currículo moderno, basado en las pedagogías de las habilidades y competencias. Esas políticas curriculares reproducen el tripié de una "nueva agenda" de políticas públicas basadas en el trípode de accountability, control y estandarización, alterando el sentido de la calidad de la educación reducido al ámbito del "aprendizaje".

PALABRAS-CLAVE

políticas curriculares; red estatal de enseñanza de São Paulo; trabajo docente. 


\section{INTRODUÇÃO}

Os anos de 1990 foram marcados pelo processo de universalização do ensino fundamental e ampliação do atendimento ao ensino médio e à educação infantil. A Lei de Diretrizes e Bases da Educação Nacional (LDB/1996) (Brasil, 1996), retomando preceitos constitucionais, apontava para a redução das desigualdades educacionais por meio de uma educação fundamentada na liberdade e solidariedade humanas, formando um jovem cidadão preparado para o convívio social, bem como para o mundo do trabalho e a continuidade dos estudos.

Nesse contexto, o currículo na rede de ensino estadual, na segunda metade dos anos de 1990 e na primeira dos anos 2000, foi organizado com base nos Parâmetros e Diretrizes Curriculares Nacionais. Durante esse período, e acompanhando as tendências presentes até então em nível nacional, as avaliações em larga escala e o pagamento de bônus salarial aos profissionais da educação, associados ao desempenho dos estudantes nessas avaliações, influenciaram, em certa medida, a organização curricular e o trabalho do professor nas instituições públicas de educação básica da rede estadual paulista. Nosso artigo pretende contribuir para a compreensão desse fenômeno, que envolve padronização, controle e a contraparte de um modelo de responsabilização bem específico, reconhecido como accountability.

Em nível nacional, no período de 2001 a 2012 foram publicadas as novas Diretrizes Curriculares Nacionais da Educação Básica, isto é, "as diretrizes que estabelecem a base nacional comum, responsável por orientar a organização, a articulação, o desenvolvimento e a avaliação das propostas pedagógicas de todas as redes de ensino brasileiras" (Brasil, 2013). O debate redireciona-se quando, nos anos de 2010, a tendência já prevista na LDB/1996 e no Plano Nacional de Educação (PNE 2014-2024) (Brasil, 2014) para a criação de uma Base Nacional Comum Curricular (BNCC) avança com a crescente participação de "promotores privados" (Cássio e Catelli Jr., 2019) nos debates públicos das reformas educacionais. Acompanhando essa reorganização educacional, o Programa São Paulo Faz Escola (SPFE), instituído pela Resolução da Secretaria da Educação (SE) 76/2008 (São Paulo, 2008e), marca a diferença com os parâmetros e diretrizes curriculares.

É preciso adicionar a essa série de fatos novos elementos na composição de uma política curricular. $\mathrm{O}$ processo de instituição de uma BNCC, finalizado somente em 2018, foi acompanhado e assimilado pela Secretaria Estadual de Educação de São Paulo (SEE-SP) ${ }^{1}$, como fica evidenciado em Resoluções como a SE 18/2016 (São Paulo, 2016) e a SE 55/2017 (São Paulo,2017b), que criaram comitês para planejamento e implementação da BNCC, ainda quando tal documento normativo se encontrava em fase de elaboração. Com praticamente uma década de antecedência, a rede estadual paulista adiantou-se a esse processo nacional que culminou na BNCC.

1 De acordo com a Resolução SE 18, de 2 de maio de 2019, a sigla da Secretaria da Educação passou a ser SEDUC-SP. Neste artigo, optou-se por usar a sigla encontrada nos documentos consultados, a saber, SEE-SP, visto que o período analisado é anterior à mudança. 
Isso remete a pensar nas mudanças que vêm ocorrendo no campo educacional há algumas décadas, orientadas pelas conferências internacionais de educação, cujo símbolo é o relatório para a Organização das Nações Unidas para a Educação, a Ciência e a Cultura (Unesco) da Comissão Internacional sobre Educação para o século XXI, coordenado por Jacques Delors, em que são apresentados os quatro pilares para a educação ao longo da vida: aprender a conhecer, aprender a fazer, aprender a conviver, aprender a ser (Delors, 2000). Esse conjunto de aprendizagens aprofunda os modelos introduzidos pelo Relatório Faure, também resultado dos trabalhos da Unesco, intitulado "Aprender a ser: a educação do futuro" (Faure et al., 1972), que desloca a educação compreendida como "transmissão de conteúdos" para uma "aprendizagem constante", ao longo de toda a vida e presente na multiplicidade de situações. Coincidência ou não, esses relatórios surgem em momentos centrais de implementação de novos modelos de gestão pública, conforme sugerem alguns autores (Laval, 2004; Biesta, 2013).

Biesta (2013) extrai disso uma consequência interessante. Em primeiro plano, percebe um deslocamento nos discursos das políticas educacionais. Quando, por exemplo, os documentos da SEE-SP passam a colocar no centro do debate o problema da "aprendizagem", não se trata apenas de um aggiornamento do vocabulário da gestão educacional com padrões internacionais, mas uma mudança de paradigma que afeta as políticas da educação e o próprio modo de conceber os problemas da vida escolar. Há um deslocamento do que ele chama "linguagem da educação" para a "linguagem da aprendizagem” (Biesta, 2013). À primeira vista, trata-se de uma denúncia do autor sobre a ascensão do termo "aprendizagem" ao lado do declínio do termo "educação" nos documentos nacionais e internacionais das políticas educacionais. No entanto, não se trata apenas de uma troca de vocábulos, pois, como lembra o autor, a linguagem "torna possível alguns modos de dizer e de fazer", assim como torna impossíveis ou difíceis outros modos de dizer e de fazer (Biesta, 2013, p. 29). De outro modo, no apagamento da educação e sua linguagem emerge o predomínio da linguagem da aprendizagem, ou melhor, a "learnification" [aprendificação] (Biesta, 2012, p. 816) e suas consequências nos processos de aprendizagem, especialmente a estreita individualização de seus processos. Acompanhamos esse diagnóstico nas leituras dos documentos e resoluções para entendermos o que se valoriza e o que se deixa de valorizar nas propostas curriculares do estado de São Paulo.

$\mathrm{Na}$ esteira dessa lógica, substitui-se o direito à educação pelo direito à aprendizagem de modo a reformular os processos da vida escolar e mesmo o modo de trabalho docente em vista dos resultados tornados visíveis pelas avaliações de larga escala produzidas pela SEE-SP. As próprias escolhas curriculares passam a ser decididas, como veremos, em conformidade com aquilo que se valoriza como fundamental no interior da linguagem da aprendizagem. Decerto, com essa mudança de paradigma, foi possível "expressar ideias e compreensões que eram um tanto difíceis de articular por meio da linguagem da educação" (Biesta, 2013, p. 30). Abre-se, por exemplo, a oportunidade de avaliar em larga escala e identificar problemas de aprendizagem em uma rede tão ampla e complexa como a do estado de São Paulo. Todavia, e aqui está o 
risco que pretendemos demonstrar ao longo deste artigo, algo da linguagem da educação perde-se na medida em que se assume a aprendificação como único fio condutor das políticas educacionais. A finalidade dos processos passa a ser a fotografia extraída dos índices do exame que, por sua vez, passa a comandar toda a hierarquia de decisões no interior da vida escolar.

Atentemos para o quanto os rankings nessas avaliações locais e internacionais preocupam gestores e professores. Tal índice apoia-se em um argumento importante de justiça social, que defende o acesso de todos à educação de mesma qualidade. Nisso, os níveis de aprendizagem passam a constituir um valor normativo importante, compreendendo como cada estudante vem se desenvolvendo com o currículo oferecido pela escola. A té então, um argumento plausível e que auxilia pensarmos um debate em torno da qualidade da educação. Contudo, a contrapartida desse padrão de controle, até importante para avaliar a qualidade de serviço oferecido na rede estadual paulista, localiza-se nos termos da Nova Gestão Pública.

Assim, essa avaliação diagnóstica da rede combina elementos de responsabilização (accountability) e de escolhas muitas vezes reduzidas aos padrões de qualidade previamente estabelecidos e alheios às demandas da própria localidade da escola. Desde o ranking, carimbam-se identidades perigosas de "escolas malsucedidas" e, em alguns casos, de "professores malsucedidos". No descompasso dessa responsabilização, diretores e professores em defesa da escola e suas práticas acusam "pais desinteressados", "alunos problemas" ou diagnosticados com algum tipo de "déficit de aprendizagem". Nesse conjunto de figuras da comunidade escolar, aprofundam-se mais e mais os marcos de desigualdades nas escolas paulistas.

Diante de um cenário de políticas educacionais cada vez mais centralizadas e padronizadas, como no período estudado, é cabível a ironia existente nesses processos apresentada por Biesta (2012, p. 411): quando a responsabilização é "limitada à escolha a partir de um cardápio fixo", falta-lhe a dimensão democrática. Em outros termos, a pretensa elasticidade da escolha é restrita ao que se lhe oferece para decidir. Basta notar que, a despeito da constante queixa de gestores e professores, isso não significa uma crescente participação dos pais e estudantes na definição das formas e conteúdos escolares. Sobre essas desmedidas, Dunker (2020) traz a imagem da "escola de Procusto", aproveitando-se do mito que trata justamente das normas e valores estabelecidos por uma medida de valor único, na qual o que escapasse do padrão deveria ser adaptado, ainda que isso significasse a deformação de suas particularidades. $\mathrm{O}$ mito torna-se ainda mais interessante quando o próprio Procusto é devorado por sua norma, uma vez que nem sequer ele, que instaurou esse padrão, poderia ser admitido como referência dessa medida.

Sob a luz das normatividades e seus padrões, passam a ser importantes os documentos que referenciam essas novas medidas. Tendo em vista a compreensão dos sentidos e significados desse processo como formas de centralização e padronização curriculares com efeitos de responsabilizações a que o trabalho docente fica cada vez mais submetido, a política curricular do estado de São Paulo, no período de 2007 a 2018, foi analisada com base na legislação, tais como resoluções e portarias da SEE-SP. 
Do ponto de vista metodológico, realizaram-se pesquisa documental e bibliográfica. Foi conduzido um levantamento da legislação nacional e do estado de São Paulo utilizando-se principalmente os sites do MEC e da SEE-SP. Para a localização de algumas leis, recorreu-se ao Portal da Legislação-Planalto. A leitura da legislação permitiu a descrição e a análise, em termos legais, das políticas curriculares no estado de São Paulo, nos aspectos centrais, com destaque para o Programa SPFE, principal política curricular do governo paulista no período em estudo, que abrange o conjunto das escolas da rede de ensino; e para o Programa de Ensino Integral (PEI), de 2012, que, embora com abrangência restrita, também operou mudanças no currículo escolar.

Desta introdução às considerações finais resulta a apresentação de dois tópicos. No primeiro, discute-se a nova agenda curricular adotada a partir de 2007. No segundo, as políticas curriculares do governo paulista são analisadas com base no Programa SPFE e na proposta curricular do PEI, seguidas de um exame que parte dos deslocamentos próprios à lógica curricular de uma escola em busca da sintonia com a realidade de seus estudantes, provocando deslocamentos significativos nos debates curriculares que se configuram no "Projeto de Vida". Nas considerações finais, concluímos que este período demonstra um aprofundamento das políticas curriculares em torno da linguagem da aprendizagem, configurando tanto uma "escola das competências" quanto seu correlato na função docente, o "professor competente".

\section{UMA NOVA AGENDA CURRICULAR NA EDUCAÇÃO PAULISTA}

A análise de políticas curriculares permite compreender em quais projetos, interesses e finalidades o currículo escolar se encontra inserido. Segundo Apple (2008), o currículo não se configura como um documento neutro e não é apenas um rol de conteúdos cuja aprendizagem é esperada dos estudantes. Ele é também expressão da forma como a escola organiza as relações de poder e atribui significados aos processos educativos. Decerto, as instituições de ensino não estão apartadas de interesses e conflitos sociais, seja em seus objetivos, seja no que se espera de seus resultados educacionais e sociais. Há na escola e nos currículos um compromisso com a manutenção do status quo, que contribui para a reprodução da desigualdade e do controle social. Mas há também questionamentos em relação às desigualdades, aos preconceitos e às discriminações que tensionam o papel reprodutor da escola algo que reflete o currículo como práxis e território de disputa (Gimeno Sacristán, 2000; Arroyo, 2011) à sombra de um projeto ideológico hegemônico.

Nesse sentido, é possível analisar as políticas curriculares do estado de São Paulo, a partir de 2007, como a implantação de uma espécie de "nova agenda" curricular. Em agosto daquele ano, a SEE-SP anunciou oficialmente um plano de reestruturação da política educacional paulista (São Paulo, 2007b). No texto de divulgação da nova agenda, destacam-se aspectos da política curricular, tais como: elaboração e divulgação das propostas curriculares da educação básica de São Paulo, também com a indicação das expectativas de aprendizagem para todos os estudantes e orientações metodológicas para a implantação do currículo; diversificação curricu- 
lar do Ensino Médio, com itinerários diversos, sobre uma base comum com ênfase no domínio da língua portuguesa, da linguagem científica, artística, computacional e uma língua estrangeira moderna, adotando uma ou mais modalidades de habilitação técnica profissionalizante; criação da função do Professor Coordenador (PC), que deve atuar como apoio pedagógico para implantar essa nova política curricular; e foco nos sistemas de avaliação em larga escala, incluindo políticas de incentivos remuneratórios aos profissionais da educação para atingir as metas propostas e na gestão para resultados.

É nesse contexto que, no ano seguinte ao anúncio da nova agenda, a Resolução SE 76 (São Paulo, 2008e) estruturou a Proposta Curricular do Estado de São Paulo para o ensino fundamental e médio, estabelecendo um currículo comum, padronizado para toda a rede estadual, como parte do Programa SPFE. Em 2009, efetua-se tal política com a entrega de materiais didáticos destinados às escolas estaduais como os denominados Cadernos do Professor, bem como o do Gestor e dos Alunos.

Todo esse processo de centralização curricular evidencia uma forte tendência à diminuição da autonomia docente na formulação e na execução da proposta curricular e pedagógica, minando assim processos de construção coletiva na escola. Dessa forma, articulada à política de centralização curricular paulista, a Resolução SE 74 (São Paulo, 2008d) regulamentou o Programa Qualidade da Escola (PQE). Tal programa estruturou a implantação do Índice de Desenvolvimento da Educação do Estado de São Paulo (Idesp).

No âmbito dessa política, o Sistema de Avaliação de Rendimento Escolar do Estado de São Paulo (Saresp) passa a ser utilizado como base para a composição do Idesp, orientando o cálculo da bonificação por resultados, paga anualmente aos servidores da educação (São Paulo, 2009) e regulamentada pela Lei complementar no 1.078 (São Paulo, 2008b). Com essa política, as metas, os índices, os fluxos de matrículas, as transferências e a evasão de alunos são elementos componentes do cálculo do Idesp. Tais estatísticas são apresentadas como pauta norteadora do currículo e das atividades cotidianas escolares da rede estadual paulista, conformando um sistema de orientação do trabalho de gestores e professores pelos resultados obtidos.

Assim, o estado de São Paulo estrutura uma prática educacional baseada numa padronização curricular e em resultados medidos por meio de exames periódicos, configurando índices e rankeamentos dos estabelecimentos de ensino, característicos das políticas neoliberais, conforme indicado por Dardot e Laval (2016). Na escola em que impera o direito à aprendizagem em detrimento do direito à educação e a gestão para resultados, o esforço volta-se para transformar o professor em cumpridor de metas e os estudantes em bons aprendizes e conformados consumidores (Biesta, 2013; Linhart, 2014).

\section{POLÍTICAS CURRICULARES NA REDE ESTADUAL PAULISTA}

Tendo em vista as políticas educacionais que surgem da nova agenda da SEE-SP, analisamos mais detidamente a política curricular expressa no Programa SPFE e no PEI e como os temas transversais se articulam a esses programas. 


\section{PROGRAMA SÃO PAULO FAZ ESCOLA}

O Programa SPFE tornou comum os conteúdos e a proposta educacional no território paulista visando à melhoria da qualidade da educação, conforme anunciado pela SEE-SP. O SPFE visa superar o baixo desempenho dos alunos nas avaliações externas por meio de mudanças na gestão e nos procedimentos de avaliação internos à escola, sempre tendo o currículo como base. Esse currículo expressa-se na iniciativa da escola em responsabilizar-se por sua aplicação (Fini, 2009) e revela o que é específico de cada escola em construir e gerenciar o seu projeto pedagógico conforme um padrão mensurado pelos resultados das avaliações externas. De acordo com a Resolução SE 76, a implantação do SPFE decorre da necessidade de

estabelecer referenciais comuns que atendam ao princípio de garantia de padrão de qualidade previsto pelo inciso IX do artigo $3^{\circ}$ da Lei de Diretrizes e Bases da Educação Nacional — Lei no 9.394/96; subsidiar as equipes escolares com diretrizes e orientações curriculares comuns que garantam ao aluno acesso aos conteúdos básicos, saberes e competências essenciais e específicas a cada etapa do segmento ou nível de ensino oferecido. (São Paulo, 2008e, p. 1)

A reforma curricular, apresentada no documento Proposta Curricular do Estado de São Paulo (São Paulo, 2008c), estabelece o objetivo de "aprimorar o trabalho pedagógico e docente [...], em parceria com seus professores, coordenadores, assistentes pedagógicos, diretores e supervisores” (São Paulo, 2008c, p. 7). No centro da proposta estava a criação de um currículo comum para toda a rede, cujos princípios centrais são a escola que aprende, o currículo como espaço de cultura e as competências como eixo de aprendizagem. As ações anunciadas no SPFE englobam um conjunto de decisões estabelecidas por normas legais, com repercussão nas atribuições dos profissionais da educação, nos procedimentos didático-pedagógico das escolas e no currículo. Para a implementação da Proposta Curricular do Estado de São Paulo, requer-se do diretor escolar e do professor coordenador o papel de liderança na orientação das atividades didático-pedagógicas a serem desenvolvidas em sala de aula, tendo como referência o material curricular produzido pela SEE-SP.

Um aspecto importante a ser considerado na análise da Proposta Curricular é a parceria da SEE-SP com instituições privadas para produção do material. Os cadernos foram elaborados pela Fundação Vanzolini, com participação de um conjunto de profissionais responsáveis por cada área do conhecimento (São Paulo, 2008a). Nota-se aqui uma zona híbrida de parceiros públicos-privados que transitam entre o campo estatal e as diversas frentes da parceria. Além da contratação dessa Fundação, a SEE-SP contratou grandes editoras e/ou gráficas por meio de edital público para impressão e distribuição do material às escolas. Toda a estrutura mobilizada para a confecção dos materiais didáticos dos alunos da rede pública paulista foi cercada de críticas e polêmicas. Soma-se a isso o fato de o material distribuído aos professores e estudantes conter erros. 
O primeiro deles, com repercussão nacional, foi o erro no caderno de Geografia do $6^{\circ}$ ano do ensino fundamental ${ }^{2}$, o que contribuiu para manifestações contrárias por parte de professores em relação à implementação da Proposta (Zan, 2012). Sobre o episódio, a SEE-SP limitou-se a informar, em nota, que os erros eram de responsabilidade da empresa que produziu o material e que as escolas tinham sido alertadas sobre falhas por meio do site, enquanto a Fundação Vanzolini se esquivou dizendo que o material foi produzido sob a supervisão da SEE-SP. Um fato interessante para reflexão: de um lado, a SEE-SP empenhou um discurso de prestação de contas por parte das escolas e seus professores; de outro, a responsabilidade é diluída ou mesmo obscurecida entre os parceiros quando a questão da accountability se volta para os problemas de gerenciamento dos programas.

No início de 2008, os materiais enviados às escolas foram o Jornal do Aluno e a Revista do Professor, intitulados posteriormente de Cadernos do Aluno e do Professor. Foram elaborados quatro volumes do Caderno do Professor, um por bimestre, para todas as disciplinas. $\mathrm{O}$ material possui sequências didáticas e sugestões de trabalho para orientar as aulas. Com vistas à melhoria dos materiais, a SEE-SP solicitou devolutiva dos professores e gestores, que foram em alguma medida incorporadas. Alheia a quaisquer projetos pedagógicos já desenvolvidos nas escolas, a SEE-SP definiu também que o Caderno do Aluno seria específico por disciplinas e por bimestre, caracterizando-se como material de referência pessoal do aluno, no qual ele registraria anotações, faria exercícios e desenvolveria as habilidades.

Após um ano de aplicação dos materiais produzidos pelo SPFE nas escolas da rede paulista, o Saresp de 2009 foi elaborado tendo como base a nova Proposta Curricular. Segundo a SEE-SP ${ }^{3}$, a participação na avaliação foi recorde: $77 \%$ dos 2,5 milhões de alunos da rede realizaram o exame. Escolas municipais e particulares também participaram. Em 2010, a SEE-SP divulgou a consolidação do Currículo com base nos bons resultados da implantação da Proposta Curricular, avaliados pelo Saresp nas devolutivas do corpo docente e na voz da comunidade escolar. Os cadernos do aluno foram atualizados em 2011 e o Programa SPFE permanece em vigor na rede estadual paulista, com atualizações e adequações do material à BNCC.

Não apenas docentes e discentes receberam um material padronizado, mas também os gestores, com o Caderno do Gestor, completando o processo de implantação do programa nas escolas, também na figura dos professores coordenadores e diretores. Conforme ressaltam Carvalho e Russo (2016), como forma de melhor implementar a pretendida reforma, a responsabilidade do professor coordenador foi intensificada com o trabalho de planejar nas escolas estratégias para atingir as metas de desempenho estabelecidas pela SEE-SP. Assim, o Caderno do Gestor: gestão

2 A apostila apresentou duas vezes o Paraguai no mapa da América do Sul e ainda inverteu a localização do Uruguai e Paraguai. O erro foi apresentado nos cadernos do aluno e do professor. Outro problema foi a não inclusão do Equador no mapa. Sem isso, o aluno não teve informação para responder à seguinte questão proposta: quais são os países sul-americanos que não fazem fronteira com o Brasil? (Coissi, 2009).

3 Informações localizadas em: http://www.escoladeformacao.sp.gov.br/portais/Default. aspx?tabid=1208. Acesso em: 20 abr. 2020. 
do currículo na escola (São Paulo, 2008a) subsidia a atuação desse profissional no processo de implementação da nova proposta. $\mathrm{Na}$ apresentação do volume 1 desse documento, a Secretária de Educação afirma que o ano de 2008 seria um divisor de águas para a educação ${ }^{4}$. Dessa forma, embora os gestores não tenham sido chamados a colaborar com a construção da proposta curricular, foi-lhes atribuída a missão de divulgá-la e implementá-la (Maldonaldo, 2013).

Em certa medida, o SPFE expressa a concepção da SEE-SP de que, por meio de orientações precisas sobre o que e como ensinar e o controle do trabalho do professor, os estudantes podem apresentar melhores desempenhos nas avaliações externas. Passa a operar aqui o que Masschelein e Simons (2017,p. 142) denominam "cultura de qualidade". Todo o aparato de avaliações de desempenho, nesse sentido, cria uma espécie de "olho da qualidade que tudo vê". Uma "polícia de cultura" que regula se a cultura de qualidade está presente. Com isso, a incapacidade ou a recusa de prestar contas é vista com desconfiança ou sinal de falta de qualidade. E, assim, nesse "regime policial" da qualidade, o professor doma a si mesmo: "submete-se a um tribunal de qualidade e obedece às leis da qualidade de serviço" (Masschelein e Simons, 2017, p. 143).

Com efeito, a melhoria nos índices das avaliações externas foi associada à implementação do SPFE. No discurso dos idealizadores da proposta, a elaboração dos cadernos ocorreu com o objetivo de facilitar o trabalho do professor em sala de aula no cumprimento de suas metas. Trabalho "facilitado" a tal ponto que, segundo Boim (2010), os professores ficaram responsáveis meramente pela reprodução dos conteúdos, sem efetivamente conceber seu material de trabalho. A autonomia do professor e a liberdade de realizar o planejamento pedagógico foram pouco consideradas nesse processo. Cria-se, assim, a figura de um funcionário domesticado, o "professor competente", cujo perfil profissional "funciona como instrumento para avaliar, ajustar e desenvolver o profissionalismo do professor" (Masschelein e Simons, 2017,p. 140). A lista de funções, competências e subcompetências ganha uma complexidade na rede de saberes a ser desempenhado, que assumem vida própria.

Como resultado, os autores denunciam que desaparece - ou ao menos silencia - "o professor atencioso que está verdadeiramente dedicado à causa" (Masschelein e Simons, 2017, p p. 141). Domado pelo universo das habilidades e competências, anula-se o ofício docente, aquele que, na oficina da sala de aula, operava com conhecimentos, habilidades e atitudes que dirigem atenção ao mundo. Resta um "professor flexível", alguém que não é mais "arrebatado por seu assunto e vive para ele, mas alguém que pode ser arrebatado por tudo — na medida em que a demanda exija" (Masschelein e Simons, p. 146). O que os autores sugerem é que esse "mal-estar" da educação tem a ver com a centralização dos processos educacionais, sua gestão na forma de resultados de desempenho e a desvalorização das dinâmicas da sala de aula que levem em consideração as singularidades tão próprias dos processos de aprendizagem.

4 Informação disponibilizada em: http://www.rededosaber.sp.gov.br/portais/Portals/18/ arquivos/CADERNO_GESTOR_FINAL_red.pdf. Acesso em: 12 mar. 2020. 


\section{O CURRÍCULO NO PROGRAMA DE ENSINO INTEGRAL}

O PEI foi implementado em 2012 pela Lei Complementar no 1.164/2012 (São Paulo, 2012a), tendo em vista a ampliação do tempo de permanência dos estudantes na escola. Conforme a Resolução no 52/2014 (São Paulo, 2014), que regulamenta a organização e o funcionamento das escolas que aderiram ao programa, ele tem como objetivo a formação de indivíduos solidários, autônomos e competentes, com base no desenvolvimento pleno da pessoa humana e no preparo para o exercício da cidadania.

O novo modelo de ensino integral, inspirado no modelo desenvolvido em Pernambuco, envolve mudanças na abordagem pedagógica, no conteúdo do currículo e na carga horária. Visando à "formação de um jovem autônomo, solidário e competente, o Programa apoia-se em quatro princípios teórico-filosóficos: 'A Educação Interdimensional, A Pedagogia da Presença, Os 4 Pilares da Educação para o Século XXI e o Protagonismo Juvenil”' (São Paulo, 2019, p. 13). Com base nesses princípios, a SEE-SP pretendia implantar um "currículo integralizado e diversificado", cuja matriz deve ser flexível e contemplar atividades que envolvam estudantes, professores e gestores.

Do ponto de vista curricular, essa perspectiva educativa estrutura-se em dois eixos pedagógicos: Projeto de Vida (plano de futuro acadêmico e profissional para estudantes); Protagonismo Juvenil (estímulo à autogestão do aprendizado, rumo ao enfrentamento dos problemas no cotidiano escolar, na comunidade e na vida social). Protagonismo Juvenil é um conceito recorrente em Costa (2006), cuja proposta é a autonomia dos jovens, mediada pelo professor e atrelada a atitudes e iniciativas desenvolvidas na escola e fora dela, contribuindo assim para a construção de seu Projeto de Vida. Voorwald e Souza (2014), ao defenderem o modelo do PEI, apropriam-se de conceitos como Protagonismo Juvenil e Projeto de Vida, acrescentando elementos como os Líderes de Turma, Clubes Juvenis e a Tutoria. A combinação desses conceitos nas escolas PEI leva a práticas curriculares nas quais se evidencia uma espécie de promoção de autonomia supervisionada, pois pressupõem que as atividades sejam orientadas e tuteladas pelos educadores.

A matriz curricular das escolas que aderiram ao PEI é composta dos diferentes componentes curriculares da base nacional comum e da parte diversificada de atividades complementares e disciplinas eletivas (São Paulo, 2014).

De acordo com o documento Diretrizes do Programa Ensino Integral, a concepção de avaliação do PEI está apoiada no pressuposto explicitado por Perrenoud de que mudanças na avaliação escolar demandam mudanças na própria escola, uma vez que avaliar envolve o estabelecimento de critérios e valores em torno dos processos educativos. Assim, a avaliação no PEI "pressupõe não apenas repensar as concepções e princípios avaliativos, mas também, e principalmente, pensar a própria escola, suas finalidades e sua função social" (São Paulo, 2019, p. 22). Uma "avaliação $360^{\circ}$ ", em que "todos se avaliam e são avaliados tanto pelos demais educadores como pelos alunos", conforme sugere Fodra (2015, p. 4), expressando o que Masschelein e Simons (2017) denominam de panóptico da avaliação de qualidade das competências e habilidades. 
O PEI envolve também um redimensionamento das condições de trabalho dos professores, com a introdução do Regime de Dedicação Plena e Integral (RDPI), que estabelece jornada de 40 horas semanais, e da Gratificação de Dedicação Plena Integral (GDPI), de 75\% do salário-base (São Paulo, 2012a, 2012b). Com isso, supõe-se a criação de condições mais adequadas de trabalho, mas por outro lado se institui um clima de insegurança nas escolas, uma vez que o professor pode ter sua participação no projeto encerrada mediante o não cumprimento dos requisitos estabelecidos pela SEE-SP. Eis aqui, sob outra forma, um redimensionamento do lugar docente na escola, domado por outra estratégia: "a profissionalização através da pressão da responsabilidade” (Masschelein e Simons, 2017, p. 141).

Desenha-se um perfil do profissional competente submetido a "um chicote na mão do governo", tecido pelas habilidades e competências, usado para domar não só a escola, mas também os professores (Masschelein e Simons, 2017, p. 140). Não se trata, claro, de uma responsabilidade que leve em consideração o mundo à volta das experiências e preocupações do docente atencioso. De outro modo, é uma responsabilidade "domada", própria à accountability: "a capacidade de resposta tendo em vista a prestação de contas", um esvaziamento da "responsabilidade pedagógica", que demanda o tempo para o cuidado e a atenção aos elementos de aprendizagem, reduzida a uma responsabilidade compreendida como "a justificativa de resultados e seus retornos" (Masschelein e Simons, 2017, p. 145), estruturada pelo tempo das avaliações e dos processos que geram esse resultado. Talvez, para evitar esse contraste, o eixo curricular no PEI tenha um deslocamento significativo.

A organização do trabalho pedagógico no PEI apoia-se, principalmente, no desenvolvimento do Projeto de Vida, estratégia central para um modelo pedagógico que defende o protagonismo dos estudantes e o envolvimento de todos os profissionais da escola no desdobramento de ações/atividades relacionadas ao Protagonismo Infantil, à Educação Emocional e às Diferentes Linguagens (teatro, música, dança e artes visuais, cultura do movimento). Nos anos finais do ensino fundamental e no ensino médio é trabalhado também o eixo Protagonismo Juvenil, no qual o aluno é estimulado a desenvolver soluções para problemas reais observados na vida social; os Clubes Juvenis, organizados pelos alunos; e a Tutoria, que consiste no acompanhamento do Projeto de Vida.

Não obstante as intenções de maior protagonismo discente no processo educativo, declaradas nos materiais que orientam a implementação do PEI, a pesquisa de Quirino et al. (2018) constatou que o currículo continua centrado na realização das atividades do Caderno do Aluno, com pouco espaço para o trabalho criativo e crítico. Nas palavras dos estudantes entrevistados pelos autores, "o dia se resumia [...] a resolver questões da apostila" (Quirino et al., 2018, p. 88). Ainda de acordo com Quirino et al. (2018), os Clubes Juvenis eram um dos "momentos do dia em que os estudantes podiam criar espaços coletivos para discutir temas, propor ações, sem a rigidez da gestão escolar" (Quirino et al., 2018, p. 88). Sobre isso é importante lembrar a advertência de Cavaliere (2014) para os rumos que a extensão do tempo de permanência dos estudantes na escola podem tomar quando desprovida de um projeto pedagógico articulado, com vistas à integração das diversas dimensões de desenvolvimento e formação das crianças, adolescentes e jovens. 
Outra questão em relação ao PEI é seu efeito sobre as escolas da mesma região. Como descrito, a organização e o funcionamento do PEI diferem daqueles do conjunto das escolas da rede, existindo uma espécie de estrutura paralela. Ainda como parte dos estudos de Quirino et al. (2018), os pesquisadores verificaram que entre 2011 e 2016 houve melhor desempenho no Idesp das escolas PEI em relação às demais de uma mesma região, o que indicou, num primeiro momento, efeitos positivos do programa. No entanto, as escolas PEI tendem a ficar com os estudantes de melhor nível socioeconômico, que podem disponibilizar maior tempo aos estudos, e aqueles que apresentam melhor rendimento escolar, centrifugando para as escolas vizinhas, numa mesma região, aqueles que não correspondem adequadamente às pretensões do PEI.

Essas desigualdades socioespacial e educacional decorrentes da implementação do PEI têm sido sinalizadas por diversos estudos (Batista et al., 2016; Grosbaum e Falsarella, 2016; Vieira et al., 2016; Girotto e Cássio, 2018) e constituem desafios às políticas públicas para a educação básica no que se refere à ampliação da jornada escolar.

Há que se pensar em que medida o PEI e o Programa SPFE estão em conexão. De um lado, temos um projeto de escola submetido a um regime cada vez mais padronizado, voltado para os resultados de melhoria no desempenho discente, das avaliações externas aos processos internos à escola. Esse projeto encontra-se, nas diferentes formas, em ambos os programas da rede pública de ensino paulista. De outro, os estudos indicam certa cisão na implementação desses programas curriculares, gerando nas escolas PEI um aspecto de modelo de ensino destinado a poucos, gerando desigualdades na região em que ocorre.

Com efeito, é interessante que, embora as escolas PEI impulsionem um debate sobre ensino integral voltado a atender às necessidades individuais, o risco de padronização e esvaziamento dos processos pedagógicos não é pequeno quando um tal modelo se estabelece em um contexto de gerenciamento por resultados. Essa é uma hipótese que se nota pelo modo como o tempo escolar é ocupado pela lógica das avaliações, compreendendo por vezes o maior tempo dentro da escola sem uma reflexão mais detida dos espaços, dos tempos e, também, dos saberes na escola (Galian e Sampaio, 2012).

Afinal, em que medida a lógica da educação integral se apresenta reduzida em seus potenciais, quando a qualidade da educação oferecida nesse modelo é apenas uma intensificação das padronizações e controles curriculares? Tal pergunta exige o esforço de compreensão desses programas pela lógica própria do currículo, de modo a entender qual a materialidade dessa padronização curricular presente em modelos aparentemente diversos de escola.

\section{DO INTERDISCIPLINAR À VIDA DISCIPLINADA}

Aproximar as propostas pedagógicas de diferentes modelos escolares apenas sob o olhar da implantação dos programas é interessante para compreender uma lógica externa que objetiva tais propostas curriculares em associação com modelos de gerenciamento. No entanto, é também interessante expor a própria materialidade 
do currículo em operação, organizando as relações escolares e as funções sociais que imperam em seu interior. Do contrário, não se compreende por que se sustenta esse caminho a despeito das inúmeras críticas sobre a desvalorização docente e sobre propostas pedagógicas continuamente mal avaliadas. Há algo na lógica do próprio currículo que permite a adesão da equipe educadora aos padrões de controle e qualidade ofertados pela SEE-SP. Há uma mudança que permite esse deslocamento nas funções e na linguagem da escola. E é nas práticas que compõem um currículo que isso se faz visível. Por isso, pode ser reveladora uma análise sobre os significados mobilizados pela proposta disciplinar do "Projeto de Vida". Entender a gênese desse componente passa a ser fundamental.

Desde os fins dos anos de 1980, Gimeno Sacristán (2000, p. 55) já havia compreendido uma mudança do lugar social da escola naquilo que denomina de "concepção globalizadora da educação", que carrega consigo novas exigências para o currículo, entre as quais noções de higiene pessoal, educação para o trânsito, educação sexual, educação para o consumo, prevenção contra as drogas, cultura de massas, cultura juvenil, integração no mundo adulto - além das áreas clássicas de conhecimento. Isso reflete uma mudança em todas as relações pedagógicas, incluindo nos códigos do currículo que pressupõem tanto uma pedagogia mais ativa em detrimento da formação tradicional e centrada nos conteúdos quanto a redução da linguagem da educação a uma linguagem da aprendizagem, conforme ressalta Biesta (2013) - algo implícito nas propostas de currículo paulistas desde os anos de 1990 e escancarado nos procedimentos adotados desde 2007.

Decerto, a lógica disciplinar do Projeto de Vida acompanha esse deslocamento para uma "concepção globalizada da educação". Conforme descrito no Caderno do Professor, esse componente tem como princípio "ensinar o aluno a olhar, a dizer, a escutar, a perceber a si mesmo e ao outro, a respeitar a si mesmo e ao outro, a responsabilizar-se pelo processo pessoal e coletivo" (São Paulo, 2014, p. 7). É uma instância potente para ressignificar os conteúdos clássicos e disciplinares em direção a um modelo curricular que considera o lugar do indivíduo diante dos desafios oferecidos pelo mundo globalizado.

Esse deslocamento já vinha ocorrendo desde os Parâmetros Curriculares Nacionais (PCN), com a introdução dos temas transversais. No entanto, o que salta aos olhos com o Projeto de Vida é também um deslocamento nas propostas interdisciplinares e transversais, que outrora almejavam gerar uma escola capaz de introduzir sujeitos escolares no cotidiano do mundo. Basta notar que os temas centrais que orientavam a transversalidade giravam em torno de uma mudança cultural pela globalização dos anos de 1990.

De fato, os temas transversais, em vista dos conflitos sociais e das experiências próprias de estudantes, preocupavam-se em fazer do processo educacional algo mais do que a simples transmissão de conteúdo, propiciando uma "educação para a vida", com um modelo de aprendizagem que instrumentaliza "os alunos para enfrentar os problemas do mundo real” (São Paulo, 2007d, p. 13). Segue uma tendência que se fortalece no âmbito federal, como as Diretrizes Curriculares Nacionais específicas 
aos temas transversais, que reforçam sua centralidade ${ }^{5}$ e efetivam políticas específicas no âmbito estadual (como a Lei no 12.780/2007, que institui a Política Estadual de Educação Ambiental) e mesmo a versão preliminar do Plano Estadual de Educação em Direitos Humanos (São Paulo, 2017a).

A despeito disso, o Programa SPFE segue a tendência analisada por Macedo (1999), em que os temas transversais seriam secundários à lógica disciplinar. Basta notar o eixo principal das políticas curriculares pelos resultados do Saresp e sua centralidade nas disciplinas de Língua Portuguesa e Matemática. Diante desses dois caminhos, forma-se uma certa esquizofrenia nos documentos oficiais que, segundo a autora, embora prezem pela ruptura dos modelos tradicionais de ensino em defesa de uma educação conectada com a realidade social, mantêm o caráter disciplinar com que os conteúdos são transmitidos. Trata-se de uma dupla lógica curricular, a qual afeta os procedimentos pedagógicos da escola, perdendo força o lado mais frágil e sem muitos cuidados. Associada às avaliações, o que passa a ser analisado é a confluência de agendas de um currículo padronizado em materiais didáticos, independentemente das particularidades dos contextos escolares.

O interessante é que os dois discursos (transversal e disciplinar) aparecem nos documentos de orientação e nas intenções dos gestores: a escola eficiente e produtiva é a mesma que apresenta o sujeito, independente de seu próprio contexto, ao mundo. Eis talvez um dos principais elementos dessa esquizofrenia curricular. Pois há entre esses documentos e intenções uma disputa de concepção de escola, de sua organização de tempos, espaços e trabalhos - algo fundamental para se pensar o currículo em meio a tantas mudanças estruturais (Galian e Sampaio, 2012, p. 420). No relato etnográfico de Catanzaro (2012,p. 86), é visível a influência detais padronizações em discursos de coordenadores de escolas e no desencontro de expectativas e reconhecimento pela equipe docente. É um padrão difuso na visão que o jovem tem da escola e certamente distante da passagem entre um espaço de aprendizagem e um local de encontro de sua geração (Pereira, 2016, p. 135). Nesse contraste entre a educação para a vida e a avaliação externa, acaba se reproduzindo um modelo de ensino empobrecido e já muito criticado (Apple, 2008; Freire, 2013), que se baseia em um conhecimento mínimo de leitura e de cálculo, voltado ao Saresp.

Pode-se, no entanto, notar a proposta do Projeto de Vida nas escolas PEI como um esforço para dissolver essa contradição. Nesse programa está aberta a possibilidade para outras propostas curriculares, considerando um currículo integrado e uma educação voltada para experiências de uma juventude protagonista. Em contraste com uma escola que continua oferecendo uma formação de baixa qualidade e desconectada da realidade e da necessidade dos alunos, o PEI responde com um projeto pedagógico organizado "em consonância com as necessidades e os desejos dos alunos" e com melhoras visíveis

5 Algo que podemos encontrar nos seguintes documentos: Diretrizes Curriculares Nacionais para a Educação das Relações Étnico-Raciais e para o Ensino de História e Cultura Afro-Brasileira e Africana (Brasil, 2004), Diretrizes Nacionais para a Educação em Direitos Humanos (Brasil, 2012a) e, no caso dos debates ecológicos, destacamos a Lei 9.795, de 27 de abril de 1999 (que instaura a Política Nacional de Educação Ambiental) e, posteriormente, as Diretrizes Curriculares Nacionais para a Educação Ámbiental (Brasil, 2012b). 
no "resultado da aprendizagem" (Fodra, 2015, p. 6). A autora baseia sua conclusão no crescimento de $26 \%$ do Idesp das escolas de ensino médio do programa em 2014, sem uma melhor interpretação sobre como o Projeto de Vida impacta esses resultados. Ainda que consideremos tais benefícios, é sintomático que o discurso de Fodra (2015), representativo da SEE-SP, mensure o sucesso ou o fracasso de uma política curricular nos resultados traduzidos em um índice, pelo qual essa articulação com a necessidade e os desejos de estudantes não é obviamente mensurável.

No entanto, sob a ótica do Projeto de Vida, podemos afirmar que tal perspectiva da SEE-SP não é uma discrepância, mas sim um aprofundamento da lógica das habilidades e competências, reforçando ainda mais a tendência analisada por Macedo (1999) de prevalência da lógica disciplinar sobre a interdisciplinaridade exigida pelos temas transversais. $\mathrm{Na}$ arquitetura curricular montada para o PEI, o percurso gerado em seus tempos, espaços e trabalhos gira em torno das opções do indivíduo aprendiz em um cardápio disciplinar.

À primeira vista, o chamado à responsabilidade e à participação abre possibilidades interessantes. No entanto, como bem sugere Apple (2008), é importante notar como esse discurso se estabelece na prática cotidiana escolar, no estabelecimento de normativas e ações que organizam a dinâmica e seus sujeitos, considerando-se que a escola é parte da rede de instituições de "controle social", e que tal discurso não se limita às disciplinas, mas estende-se às formas e significados que são produzidos e transmitidos nesse espaço educativo.

Essa consideração é importante uma vez que aqui está em jogo uma mudança no significado dos problemas que antes sustentavam os temas transversais e suas possibilidades de aproximar o contexto escolar da realidade social de seus estudantes. Com o PEI, é importante notar como a gramática da "gestão dos problemas" passa a ser operante. Não é à toa que o protagonismo juvenil se associa ao eixo do Projeto de Vida, este reconhecido como "o grande diferencial" do modelo escolar do PEI (São Paulo, 2019, p. 13). Tendo o Projeto de Vida como eixo central, o PEI associa o campo curricular às expectativas juvenis de futuro. Mais ainda, todo um cardápio de "escolhas" é oferecido aos estudantes, que pretensamente passariam a desenhar sua trajetória no corpo curricular da escola. Está aí justificada a presença de professores-tutores para orientar escolhas, a organização de disciplinas eletivas oferecidas aos estudantes, os "líderes" de turma, os clubes juvenis para incorporar "oportunidades de organização, gestão e convivência entre seus membros" (Fodra, 2015, p. 8). Mesmo a "orientação de estudos", que aparentemente escaparia dessa lógica de consumo das ofertas curriculares, ao oferecer "suporte para que os alunos consolidem e ampliem as habilidades previstas de forma que não apresentem novas defasagens" (São Paulo, 2014, p. 32), partilha dessa lógica. Afinal, como manter os índices de desempenho dessa escola-modelo se nos desejos e necessidades da juventude não estiverem introjetados tais valores avaliativos?

Curiosa é a gramática em que o Projeto de Vida se apresenta. Diante de uma realidade complexa e contraditória, em vez da perspectiva crítica - termo cada vez mais esvaziado nos documentos de educação - passa a valer o gerenciamento de ações e o delineamento de projetos em busca de soluções efetivas. Nesse giro curricular, os problemas do mundo, antes tratados nos temas transversais, passam a integrar a escola 
sob a forma de "gestão de crises", em que o indivíduo é convocado para escolher saídas. Como sugere Laval (2004, p. 53), o indivíduo passa a ser "responsabilizado", alguém que é protagonista "consciente das vantagens e dos custos do aprendizado que deve fazer as melhores escolhas de formação para seu próprio bem". Essa característica prolonga-se no corpo docente, que se torna "guia, tutor, mediador" a acompanhar os "indivíduos isolados no seu processo de formação" (Laval, 2004, p. 53).

Como resultado, tem-se uma transversalidade reduzida à matéria de gestão e o interdisciplinar bloqueado pela lógica disciplinar. Nessa realidade, curiosamente ficam de lado questões que escapam: problemas profundos das contradições sociais, que muitas vezes explodem nas questões de raça e gênero, passam a ser vistas como desvio programático, ou mesmo acusadas de ideologia em vista de uma educação "neutra". Neutralidade que, na melhor das hipóteses, representa a eficiência e a produtividade esperada pelas avaliações externas à sombra dos conflitos que habitam das mais diversas formas a comunidade escolar. Contradições sociais são distúrbios na máquina de resultados. Ser resiliente é imperativo para manter a esteira girando. Eis o que se espera de uma escola das competências: docentes e estudantes competentes em suas próprias escolhas, independentemente das condições sociais, econômicas e políticas que os cercam.

\section{CONSIDERAÇÕES FINAIS}

$\mathrm{O}$ retrato patente neste artigo mostra-se num certo cercamento das capacidades produtivas e das potências presentes na instituição escolar. De 2007 a 2018, pouco mais de uma década de políticas curriculares, o que se configura é uma compreensão estruturada pela padronização dos currículos, pelo controle dos procedimentos pedagógicos e a desintelectualização do exercício do magistério (Shiroma, 2018), pelas parcerias público-privadas e por uma cultura da accountability. Esses eixos analíticos evidenciam-se conforme notamos o avanço de um discurso pedagógico baseado nas habilidades e competências, reforçando uma visão míope dos processos educacionais, que são reduzidos à gramática da aprendizagem e sua eficiência e produtividade mensuradas ao ritmo das avaliações externas.

Como consequência, as propostas curriculares desse período reforçam cada vez mais uma lógica disciplinar e conteudista, com a sobrevalorização da Língua Portuguesa e da Matemática em detrimento das demais disciplinas. Com o empobrecimento curricular assim estabelecido, nada mais previsível do que uma "escola desescolarizada" (Masschelein e Simons, 2017), extasiada em um ritual constante de avaliações distantes dos complexos tecidos sociais do estado paulista.

Com o currículo centralizado, avaliado pelo Saresp, acompanhado por uma política de bonificação dos salários docentes com base no Idesp, implementa-se um elemento alheio ao contexto de cada escola. O tempo, o espaço e o trabalho que estruturam o currículo das escolas passam a ser esvaziados pelos processos avaliativos, contextualizando as escolas no território dos rankings. Diante da abstração geral dos índices, não importa o bairro em que a escola se localize, quem a frequente ou quais as potências singulares de cada projeto pedagógico. A escola das competências nutre-se dos professores e estudantes competentes. 
Decerto, não se trata de uma opção exclusiva do governo paulista. As políticas curriculares no Brasil, desde os anos de 1990, têm sido orientadas pela denominada pedagogia das competências e por uma perspectiva centralizadora do currículo escolar. Os Parâmetros e as Diretrizes Curriculares Nacionais para o ensino fundamental e médio foram importantes documentos de orientação pedagógica. As avaliações externas, também implementadas a partir dos anos de 1990, têm sido importantes instrumentos de indução dos currículos escolares em nível nacional, tendo em vista melhorar o desempenho dos estudantes nas provas, somado às políticas de bonificação do magistério vinculadas aos resultados.

No entanto, desde 2007, o caso paulista concentra em sua rede - a maior do país - mudanças no padrão dos procedimentos escolares. O que fica patente é o papel ocupado pelas políticas curriculares quando associadas a uma nova gestão pública, baseada em resultados. Padronização, controle e accountability impõem-se quando uma série de ferramentas administrativas passa a alinhar-se com uma concepção de currículo muitas vezes confundida com um modelo disciplinar, seja ele mais ou menos flexível. Apesar de toda a crítica presente nos documentos oficiais sobre os limites da educação "tradicional" " "disciplinar", esta ainda persevera na prática, reconfigurando as expectativas presentes nas avaliações de resultados.

É assim no Programa SPFE e continua a ser assim também nas escolas PEI. Mesmo que estas ofereçam um modelo pedagógico mais arrojado, prevendo didáticas que considerem estudantes corresponsáveis pelos seus próprios itinerários formativos, encontram-se pontos de corrosão. Tanto na proposta do Projeto de Vida como seu eixo central quanto na melhoria de seus resultados sob os critérios esperados pela SEE-SP, algo ainda permanece em sua sombra. À primeira vista, cresce um modelo de padronização e controle que gera um exercício de enorme pressão em sua equipe, como também um processo seletivo de seu público anterior mesmo à entrada na instituição, considerando-se os níveis socioeconômicos de seus estudantes em comparação com os demais estudantes das escolas do entorno (Quirino et al., 2018).

Sob o olhar das propostas curriculares apresentadas tanto no SPFE quanto no PEI, cresce também a cultura da accountability, em que se baseia a responsabilização pela prestação de contas. Aqui não se contabiliza apenas a responsabilização pelo céu e o inferno dos índices. Entra no cálculo também certa racionalidade das práticas pedagógicas estruturadas na individualização das aparentes escolhas, independentemente do que é oferecido. O professor "competente" na escola das competências é aquele que, a despeito das adversidades que impossibilitam a isonomia de suas tarefas, alcança os resultados possíveis no quadro de expectativas gerenciáveis (Masschelein e Simons, 2017, p. 148). O estudante "competente" é aquele eficaz e produtivo, capaz de sustentar seu "projeto de vida", fixado no "varal dos sonhos", distinto daquele que segue a ordem da "zoeira", dissonância estudantil produzida pelo contexto social de onde vivem (Pereira, 2016, p. 79) e que deve permanecer silenciada na ordem escolar das competências.

Silenciada? Talvez. Afinal, ainda que a máquina gerencial-curricular da padronização, controle e accountability se estabeleça, é preciso lembrar dos ruídos produzidos em seu interior. Eles ressoam no gestor que compreende a escola em que trabalha por um projeto pedagógico integrado a seu território; na atividade 
docente que se materializa na crítica das contradições da realidade; no instante em que estudantes ocupam escolas para que elas simplesmente não fechem. Aqui, a responsabilidade é outra e está completamente integrada com o mundo e seus desafios feitos de carne e osso.

Para compreender o significado desses termos, remetemo-nos a Hannah Arendt (2016), que apresenta um conceito de responsabilidade diretamente oposto àquele contido nos termos de accountability. Para a filósofa, a educação - e a aprendizagem que nela ocorre - contém uma responsabilidade perante o mundo e as novas gerações (Arendt, 2016): uma responsabilidade que exige, pois, o tempo do cuidado e da atenção sustentado, em especial, por vínculos intersubjetivos. É diferente da accountability e seu "cinismo de resultados" (Dunker, 2020, p. 49), cujo cumprimento é avaliado pela responsabilidade que cada um tem de "desempenhar a sua função". Cada um no seu setor: o gestor gerencia, o professor professa, o estudante estuda - e cada qual passa a ser responsável individualmente por isso. Trata-se de um modo de ver a educação apenas pelos seus fragmentos, como peças de uma grande engenharia em uma divisão nada funcional do trabalho - uma fotografia bastante distante do tom multidisciplinar da educação e sua responsabilidade pautada na ética da alteridade, tal como defendido por Arendt (2016), crítica justamente dessa ausência de pensamento na burocracia em que cada um "cumpre sua função" sem enxergar o outro.

Diferentemente dessa fragmentação, e envoltos pela mesma materialidade, os sujeitos da escola reconhecem-se como tais. Aqui, ninguém é cobrado pela abstrata "prestação de contas", mas pelo "olho no olho", pela palavra que faz circular, pela atenção e o cuidado que dedica ao mundo. $\mathrm{Na}$ densidade dessas relações, tudo o que é learnification (aprendificação) se desmancha no ar. O arquivo de avaliações enche-se de poeira, a moeda das competências e habilidades começa a perder seu valor. Basta ver o que os secundaristas mais mobilizaram quando ocuparam escolas em 2015: as cadeiras, outrora lugar de disciplinarização dos corpos, agora um ponto de onde podem explicitar seu lugar social na escola (Campos et al., 2016). Basta notar o que se demanda quando se boicota o Saresp. Aqui é outra a ordem do tempo, do espaço e das atividades, longe da reprodução eterna das avaliações vazias, do padrão que exclui e do controle que silencia.

\section{REFERÊNCIAS}

APPLE, M. W. Ideologia e currículo. 3. ed. Porto Alegre: Artmed, 2008.

ARENDT, H. Crise da educação. In: ARENDT, H. Entre o passado e o futuro. São Paulo: Perspectiva, 2016. p. 221-247.

ARROYO, M. G. Currículo, território em disputa. Petrópolis: Vozes, 2011.

BATISTA, A.A. G. et al.Política para o ensino médio: o caso de quatro estados. Cadernos Cenpec, v. 6, n. 2, p. 1-46, 2016. http://dx.doi.org/10.18676/cadernoscenpec.v6i2.359

BIESTA, G. Boa educação na era da mensuração. Cadernos de Pesquisa, v. 42, n. 147, p. 808-825, set./dez. 2012. 
BIESTA, G. Para além da aprendizagem: educação democrática para um futuro humano. Belo Horizonte: Autêntica, 2013.

BOIM, T. O que e como ensinar: proposta curricular, materiais didáticos e prática de ensino nas escolas públicas estaduais em São Paulo (2008-2009). Dissertação (Mestrado em Educação: História, Política, Sociedade) - Pontifícia Universidade Católica de São Paulo, São Paulo, 2010.

BRASIL. Lei no 9.394, de 20 de dezembro de 1996. Estabelece as Diretrizes e Bases da Educação Nacional. Brasil, 1996. Disponível em: http://www.planalto.gov.br/ccivil_03/ LEIS/L9394.htm. Acesso em: 17 jan. 2019.

BRASIL. Lei no 9.795, de 27 de abril de 1999. Dispõe sobre a educação ambiental, institui a Política Nacional de Educação Ambiental e dá outras providências. Brasil, 1999. Disponível em: https://www.camara.leg.br/proposicoesWeb/prop_mostrarinteg ra;jsessionid=50EE32BD99AF52EB7D5DB8E7E03AE765.node1 ?codteor $=634068$ \&filename=LegislacaoCitada+-PL+4692/2009. Acesso em: 17 dez. 2019.

BRASIL. Ministério da Educação. Secretaria Especial de Políticas de Promoção da Igualdade Racial. Diretrizes Curriculares Nacionais para a Educação das Relações Etnico-Raciais e para o Ensino de História e Cultura Afro-Brasileira e Africana. Brasília: MEC, SEPPIR, 2004.

BRASIL. Ministério da Educação. Conselho Nacional de Educação. Resolução no 1, de 30 de maio de 2012. Estabelece Diretrizes Nacionais para a Educação em Direitos Humanos. Brasil, 2012a.

BRASIL. Ministério da Educação, Conselho Nacional de Educação. Resolução no 2, de 15 de junho de 2012. Estabelece as Diretrizes Curriculares Nacionais para a Educação Ambiental. Brasil, 2012b.

BRASIL. Diretrizes Curriculares Nacionais gerais da educação básica. Brasília: MEC, SEB, DICEI, 2013.

BRASIL. Lei no 13.005, de 25 de junho de 2014. Aprova o Plano Nacional de Educação - PNE e dá outras providências. Brasil, 2014. Disponível em: http://www.planalto.gov. br/ccivil_03/_Ato2011-2014/2014/Lei/L13005.htm. Acesso em: 17 jan. 2019.

CAMPOS, A. et al. Escolas de luta. São Paulo: Veneta, 2016.

CARVALHO, C. P. F.; RUSSO, M. H. Políticas educacionais e itinerários de pesquisa: o programa São Paulo Faz Escola. Revista de Estudios Teóricos y Epistemológicos en Política Educativa, v. 1, n. 2, p. 193-210, 2016.

CÁSSIO, F.; CATELLI JR., R. Educação é a base? 23 educadores discutem a BNCC. São Paulo: Ação Educativa, 2019.

CATANZARO, F. O. O Programa São Paulo faz Escola e suas apropriações no cotidiano de uma escola de ensino médio. Dissertação (Mestrado em Educação) Programa de Pós-graduação em Educação, Universidade de São Paulo, São Paulo, 2012.

CAVALIERE, A.M. Escola pública de tempo integral no Brasil: filantropia ou política de Estado? Educação \& Sociedade, v. 35, n. 129, p. 1205-1222, out.-dez. 2014. https:// doi.org/10.1590/ES0101-73302014142967 
COISSI, J. Livro da rede estadual tem dois Paraguais. Folha de S.Paulo, São Paulo, 17 mar. 2009. Disponível em: https://www1.folha.uol.com.br/fsp/cotidian/ff1703200906. htm. Acesso em: 16 nov. 2019.

COSTA, A. C. G. da. Protagonismo juvenil: adolescência, educação e participação democrática. 2. ed. Salvador: Fundação Odebrecht, 2006.

DARDOT, P.; LAVAL, C.A nova razão do mundo: ensaio sobre a sociedade neoliberal. São Paulo: Boitempo, 2016.

DELORS, J. Educação um tesouro a descobrir: relatório para a Unesco da Comissão Internacional sobre educação para o século XXI. São Paulo: Cortez, 2000.

DUNKER, C. I. Paixão da ignorância: a escuta entre a psicanálise e a educação. São Paulo: Contracorrente, 2020.

FAURE, E. et al. Aprender a ser: la educación del futuro. Madri: Alianza Editorial; Paris: Unesco, 1972.

FINI, M. I. Currículo e avaliação: articulação necessária em favor da aprendizagem dos alunos da rede pública de São Paulo. São Paulo Perspectiva, v. 23, n. 1, p. 57-73, jan./jun. 2009.

FREIRE, P. Pedagogia do oprimido. Rio de Janeiro: Paz e Terra, 2013.

FODRA, S. M. O projeto de vida: escolas do programa do ensino integral. In: ASSOCIATION FOR MORAL EDUCATION, 41., 2015. Anais [...]. 2015. Disponível em: http://www.fecilcam.br/revista/index.php/anaisame/article/ viewFile/1348/835. Acesso em: 8 jun. 2020.

GALIAN, C. V. A.; SAMPAIO, M. M. F. Educação em tempo integral: implicações para um currículo da escola básica. Currículo sem Fronteiras, v. 12, n. 2, p. 403-422, maio/ago. 2012.

GIMENO SACRISTÁN, J. O currículo: uma reflexão sobre a prática. 3. ed. Porto Alegre: Artmed, 2000.

GIROTTO, E. D.; CÁSSIO, F. L. A desigualdade é a meta: implicações socioespaciais do Programa Ensino Integral na cidade de São Paulo. Arquivos Analíticos de Políticas Educativas, v. 26, n. 109, p. 1-28, 2018. https://doi.org/10.14507/epaa.26.3499

GROSBAUM, M.W.; FALSARELLA, A. M. Ensino médio, educação profissional e desigualdades socioespaciais no estado de São Paulo. Cadernos Cenpec, São Paulo, v. 6, n. 2, jul./dez. 2016. http://dx.doi.org/10.18676/cadernoscenpec.v6i2.364

LAVAL, C. A escola não é uma empresa: o neoliberalismo em ataque ao ensino público. Londrina: Planta, 2004.

LINHART, D. Modernização e precarização da vida no trabalho. In: ANTUNES, R. (org.). Riqueza e miséria do trabalho no Brasil III. São Paulo: Boitempo, 2014. p. 43-54. MACEDO, E. F. Parâmetros curriculares nacionais: a falácia de seus temas transversais. In: MOREIRA,A.F.B. (org.).Currículo: políticas e práticas. Campinas: Papirus, 1999.p. 43-59. MALDONALDO, L. R. S. Reformas educacionais na perspectiva de docentes: o programa São Paulo faz Escola. 2013. Dissertação (Mestrado em Educação) Faculdade de Educação, Universidade de São Paulo, São Paulo, 2013. 
MASSCHELEIN, J.; SIMONS, M. Em defesa da escola: uma questão pública. 2. ed. Belo Horizonte: Autêntica, 2017.

PEREIRA, A. B. "A maior zoeira” na escola: experiências juvenis na periferia de São Paulo, São Paulo: Ed. Unifesp, 2016.

QUIRINO, A. E.P. et al. A geografia do ensino integral em São Paulo. In: GIROTTO, E. D. (org.). Atlas da rede estadual de educação de São Paulo. Curitiba: CRV, 2018. p. 65-91.

SÃO PAULO. Lei no 12.780, de 30 de novembro de 2007. Institui a Política Estadual de Educação Ambiental. São Paulo, 2007a. Disponível em: https:/www.al.sp.gov.br/ repositorio/legislacao/lei/2007/lei-12780-30.11.2007.html. Acesso em: 17 dez. 2019.

SÃO PAULO. Secretaria da Educação de São Paulo cria nova agenda para educação pública. Diário Oficial, São Paulo, v. 117, n. 157, ago. 2007b. Disponível em: http:// www.saopaulo.sp.gov.br/spnoticias/ultimas-noticias/estado-lanca-10-metas-para-aeducacao-ate-2010/. Acesso em: 3 jun. 2019.

SÃO PAULO. Secretaria da Educação de São Paulo. Caderno do gestor: gestão do currículo na escola. São Paulo: Secretaria da Educação, 2008a. v. 1. Disponível em: http://www.rededosaber.sp.gov.br/portais/portals/18/arquivos/cg-vol1.pdf. Acesso em: 3 jun. 2019.

SÃO PAULO. Secretaria da Educação de São Paulo. Lei complementar no 1.078, de 17 de dezembro de 2008. Institui Bonificação por Resultados - BR, no âmbito a secretaria da Educação, e dá providências correlatas. São Paulo: SEESP, 2008 b.

SÃO PAULO. Secretaria da Educação de São Paulo. Proposta curricular do Estado de São Paulo: documento de apresentação. São Paulo: SEESP, 2008c. Disponível em: http://www.rededosaber.sp.gov.br/portais/portals/18/arquivos/propostacurriculargeral_ internet_md.pdf. Acesso em: 3 jun. 2019.

SÃO PAULO. Secretaria da Educação de São Paulo. Resolução SE-74, de 6 de novembro de 2008. São Paulo: SEESP, 2008d.

SÃO PAULO. Secretaria da Educação de São Paulo. Resolução SE-76, de 7 de novembro de 2008. Dispõe sobre a implementação da Proposta Curricular do Estado de São Paulo para o Ensino Fundamental e Médio, nas escolas da rede estadual. São Paulo: SEESP, 2008e.

SÃO PAULO.Programa Qualidade da Escola: Nota Técnica. São Paulo: SEESP, 2009. SÃO PAULO. Lei Complementar no 1.164, de 4 de janeiro de 2012. Diário Oficial do Estado de São Paulo, seção 1, p. 1, 5 jan. 2012a.

SÃO PAULO. Lei Complementar no 1.191, de 28 de dezembro de 2012. Diário Oficial do Estado de São Paulo, seção 1, p. 1, 28 dez. 2012b.

SÃO PAULO. Secretaria da Educação do Estado de São Paulo. Resolução SE-52, de 02-10-2014. Dispõe sobre a organização e o funcionamento das escolas estaduais do Programa Ensino Integral, de que trata a Lei Complementar 1.164, de 4 de janeiro de 2012, e dá providências correlatas. São Paulo: SEESP, 2014. Disponível em: http:// www.educacao.sp.gov.br/lise/sislegis/detresol.asp?strAto=201410020052. Acesso em: 5 maio 2019. 
SÃO PAULO. Secretaria da Educação do Estado de São Paulo. Resolução SE-18, de 1-3-2016. Institui Comissão Especial de mobilização para construção da Base Nacional Comum Curricular - BNCC. São Paulo, 2016. Disponível em: http://siau. edunet.sp.gov.br/ItemLise/arquivos/18_19.HTM?Time=16/09/2021\%2020:13:48. Acesso em: 30 out. 2019.

SÃO PAULO. Plano Estadual de Educação em Direitos Humanos - Versão Preliminar. São Paulo: Comitê Estadual dos Direitos Humanos de São Paulo, 2017a. Disponível em: http://www.mpsp.mp.br/portal/page/portal/cao_civel/Texto\%20 Base\%20-\%20Plano\%20Estadual\%20Educa\%C3\%A7\%C3\%A3o\%20em\%20 Direitos\%20Humanos\%20SP.pdf. Acesso em: 17 jul. 2020.

SÃO PAULO. Secretaria da Educação do Estado de São Paulo. Resolução SE-55, de 23-11-2017. Cria Comitê para planejamento de ações visando à implementação da Base Nacional Comum Curricular - BNCC, no Estado de São Paulo. São Paulo, 2017b. Disponível em: http://siau.edunet.sp.gov.br/ItemLise/arquivos/55_17. HTM?Time=01/11/2019\%2017:37:16. Acesso em: 30 out. 2019.

SHIROMA, E. O. Gerencialismo e formação de professores nas agendas das organizações multilaterais. Momento Diálogos em Educação, v. 27, n. 2, p. 88-106, maio/ago. 2018. https://doi.org/10.14295/momento.v27i2.8093

VIEIRA, S. L. et al. Reações das políticas educacionais estaduais nas escolas: um estudo de caso em escolas do Ceará, Goiás, Pernambuco e São Paulo. Cadernos Cenpec, São Paulo, v. 6, n. 2, p. 51-70. jul./dez. 2016. http://dx.doi.org/10.18676/cadernoscenpec. v6i2.360

VOORWALD, H.; SOUZA, V. Políticas públicas e educação: o novo modelo de escola de tempo integral. São Paulo: Secretaria da Educação, 2014.

ZAN, D. D. P. A concepção de ensino médio e de currículo expressa na proposta de São Paulo. Horizontes, v. 30, n. 2, p. 59-68, jul./dez. 2012.

\section{SOBRE OS AUTORES}

Márcia Aparecida Jacomini é doutora em educação pela Universidade de São Paulo (USP). Professora da Universidade Federal de São Paulo (Unifesp). E-mail: jacominimarcia@gmail.com

Silvio Ricardo Gomes Carneiro é doutor em filosofia pela Universidade de São Paulo (USP). Professor da Universidade Federal do ABC (UFABC).

E-mail: silviocarneiro@gmail.com

Ana Carolina Colacioppo Rodrigues é doutora em educação pela Pontifícia Universidade Católica de São Paulo (PUC-SP).

E-mail: accolacioppo@hotmail.com 
Raphael Bueno Bernardo da Silva é mestrando em filosofia pela Universidade Federal do ABC (UFABC). Professor da Secretaria da Educação do Estado de São Paulo (SEE-SP).

E-mail:rbuenobs@hotmail.com

Conflitos de interesse: Os autores declaram que não possuem nenhum interesse comercial ou associativo que represente conflito de interesses em relação ao manuscrito.

Financiamento: Este artigo foi produzido com base em dados da Pesquisa Política Educacional na rede estadual Paulista (1995-2018), financiada pela Fundação de Amparo à Pesquisa do Estado de São Paulo (Fapesp), Processo 2018/09983-0.

Contribuições dos autores: Administração do Projeto, Obtenção de Financiamento: Jacomini, M. A.; Análise Formal, Conceituação, Curadoria de Dados, Escrita - Primeira Redação, Escrita - Revisão e Edição, Investigação, Metodologia: Jacomini, M. A.; Carneiro, S. R. G.; Rodrigues, A. C. C.; Silva, R. B. B. da. 